\title{
Un Mano a Mano de Nobel a Nobel
}

\author{
Pablo Neruda visto por Miguel Angel Asturias
}

Pablo Neruda, poeta habitado, o podría decirse, planeta habitado. En el universo de la poesía giran los poetas que fueron, como planetas muertos, y los poetas que son, como planetas vivos. Neruda, más que ningún otro, es por excelencia el poeta habitado. Su poesía, por eso mismo, es, en mundos abiertos, la poesía que más objetos contiene, que más cosas canta, y si no canta, cuenta, y sino cuenta, dice. Dice, y dice, y dice. Los poemas de otros poetas, por lo general, son desoladores. En ellos, la palabra es misterio; enigma, substancia poética, y nada más. Una poesía en el alto vacío. En Neruda, no. La poesía está llena de todo lo que existe. ¿Es que el poeta, como un niño, quiere nombrarlo todo? ¿Es que no se conforma con sólo mirarlo, contemplarlo, tenerlo en las manos, olerlo, gustarlo, sentirlo fuera de su poesía? ¿Por eso lo traslada, va. liéndose del vocablo, de sus características, de sus símbolos, a sus cam. pos verbales? ¿Qué son las Odas elementales, como su nombre 1o dice, sino elementos naturales llevados a la poesía? No serái difícil, en el futuro, hacer un inventario de todo lo que rodeaba, en un momento dado, a Pablo Neruda, en su país natal, o bien en los lugares en que ha vivido. Porque en su poesía está, existe, es lo que la puebla. No la palabra, sin razón de ser, o la palabra que llena, como un ripio, un vacío en un verso, no, sino la palabra puesta en función de existenciaexistencia, y existencia poética. Es el poeta que vive con las cosas, por las cosas, y que las proyecta a veces colindando con la prosa, dejando el campo áureo del poema. Pero a esta sencillez de lo nominativo llega, no directamente, pues, como todos los poetas, pasa por aquél tener el alma en pena, quererse explicar la existencia, dolerse de la vida, época de la "Canción de la fiesta", Crepusculario, y luego ya más cerca del lugar a donde se dirigía, como un minero ciego golpeando las paredes 
de sus sueños, después de los Veinte poemas de amor y una canción desesperada, las incursiones más definitivas, en terreno de una poesía profundamente humana, lírica, candente con su Tentativa del bombre infinito, en las series de Residencia en la tierra, que incluyen "Las furias y las penas", "España en el corazón" y "Canto a Stalingrado". El poeta supera, rebasa el dolor propio, personal, individual, y siente no sólo su pesar, su penar, el sufrimiento del hombre que hay en él, por momentos fracasado, por instantes náufrago en su propio mar, sino el dolor del mundo, todo el dolor de pueblos que sufren, padecen, lloran, y es en contacto de esta realidad que no puede ocultarse, que Neruda deja aquellas formas de poesía, para algunos hermética, y se lanza al Canto General, que como alguna vez dije, cabe emparentarlo con la crónica de Bernal Díaz del Castillo, el cronista soldado que acompañó a Cortés en la conquista de Méjico.

$Y$ si no disuena la anécdota, fue en ese entonces cuando reanudamos, más íntimamente, nuestra amistad con el poeta chileno. Su visita a Guatemala fue inolvidable, y él la recordó muy bien en un breve recuento de aquéllos momentos. Oigámosle:

"Entré a Guatemala por las altas cumbres que la unen a Méjico, por esa carretera que brilla por entre las desiertas montañas tejidas con musgo gigantesco, atravesada por pájaros que ciegan la vida con el relámpago de fuego y de turquesa y a la que descienden manantiales, nieblas y mitologías. Luego pasé por riberas de inmensos lagos inmóviles como Atitlan, insondable, y junto a las ciudades desiertas fundadas por los dioses, encontré un pueblo fino y fulgurante, un pueblo tejedor y agrario pululando por senderos, y mercados, extrayendo ladrillos y maíz de aquellas tierras fragantes. Pero detrás de las telas asombrosas tejidas por tan antigua y delicada sabiduría, junto a los manantiales $y$ a los mercados, Guatemala estaba llena de cantos en sordina para mi oido de hombre libre, era una selva aulladora en la que hablaban los hombres en un lenguaje secreto que yo percibía, y los escritores me acogieron con recia $y$ varonil franqueza, implantándome entre ellos, como hermano".

$\mathrm{Y}$ en esa Guatemala de la que él dice: "Guatemala agonizaba. El terror y el dolor dominaban piedras y hombres. Hablábamos despacito, para que no oyeran los árboles. El Tirano era un hombre con sable y con ese sable ejercía la censura, encarcelaba, relegaba y oprimía. Respiré con los hombres de Guatemala, el aire y el humo de la angustia...".

$Y$ en ese ambiente, leí para él y para un grupo de amigos, algunos capítulo de El Señor Presidente, mi novela, que seguía inédita. Y 
le conmovió tanto que lo recordó después en un discurso: "Leyó, Miguel Angel Asturias, con la majestad de un antiguo mito. En Europa sus leyendas mayas paralizaron a los más altos. Se ha metido en la profundidad de su patria circulando en ella como una partícula viajera de su sangre, y entrando en ella hasta lo más remoto. Por eso sus palabras en leyenda o en novela, traen muchos sueños, alegrías y pasos de todos los caminos de un pueblo, y la señal de su dominio es la voz enterrada de la patria que en él canta de nuevo..."

Pero volvamos al comienzo, a Pablo Neruda, poeta habitado, planeta habitado. En Estocolmo, al recibir el Premio Nobel lo expresó: "Cada uno de mis versos quiso instalarse como un objeto palpable: cada uno de mis poemas pretendió ser un instrumento útil de trabajo; cada uno de mis cantos aspira a servir en el espacio como signo de reunión donde se cruzaron los caminos, o como fragmento de piedra, o de madera en que alguien, otros, los que vendrán, pudietan depositar los nuevos sig. nos".

La poesía del habitado poeta, del poblado planeta, habitado, poblado por todas las cosas de la tierra, del mar y del cielo, además de esta apropiación, por la poesía, de lo real, de lo que la hortaliza tiene, no sólo el jardín, y tiene la piedra, el pedregal, no la piedra preciosa, además de esta nominación mágica que las hace suyas, de su poesía, se instala como una señal de caminante ilusionado, en medio de las infinitudes planetarias, como él mismo dice de nuestra América...

Mis poemas han sido hechos, parece decir, con "las aportaciones de la tierra y el alma". El alma aquí ya es otro elemento, yo lo llamaría elemento captador, porque a los aportes terrígenos, el poeta une lo que su alma capta más allá de lo visible, en ese invisible que rodea todas las cosas, y las hace de fácil transposición a la poesía. No solamente las aportaciones de la tierra, sino las del alma, las del interior del poeta, las que él adivina, las que él conjuga, las que le dispensan el poder de crear, con las cosas de que su mano dispone, que toca, que mira, que oye, que prueba, que siente, un universo plural, cosmogónico.

Luego, otro de sus postulados, es el de la poesía como comunicación humana. "El poeta, dice Neruda, debe aprender de los demás hombres. No hay soledad inexpugnable. Todos los caminos llevan al mismo punto: a la comunicación de lo que somos. $Y$ es preciso atravesar la soledad y la aspereza, la incomunicación y el silencio para llegar al recinto mágico en que podemos danzar torpemente o cantar con melancolía; más en esa danza o en esa canción están consumados los más antiguos ritos 
de la conciencia: el de la conciencia de ser hombres y creer en un destino común. .."

Otra razón de ser de la poesía nerudiana. La onomástica, muy bien, amonedar en versos delgados como columnas, los nombres jamás dichos por otros poetas, los sencillos, los humildes nombres de las cosas jamás cantadas; pero además de la onomástica, el que el poema sirva de vínculo, que no limite, sino amplíe, que no encierre, sino abra los caminos del hombre, para la relación con los otros hombres.

$Y$ es así como en sus poemas hallan lugar las piedras de Chile, los pájaros y todo el misterio y el enigma de los antiguos peruanos, en ese glorioso poema "Alturas de Machu Picchu", lleno hasta desbordarse, de todas las resonancias mudas que encierra, para el que sabe oir, aquella ciudad hecha de piedras estelares.

Pero hay otro aspecto, para algunos poco poético, pero para mi muy entrañablemente unido a esta poesía de substancias naturales, en Neruda, su gusto por las cocinas exóticas, por los sabores encontrados furtiva y pasajeramente al degustar un vino o una bebida rara, y esto valga la segunda anécdota, nos llevó a componer juntos un libro que recoge todos los milagros de la cocina y las bebidas de Hungría.

Es ahora, el "diálogo" de dos Premios Nobel, libro preciosamente ilustrado, publicado en todos los idiomas, y en cuyas páginas se alternan prosa y poemas, estampas y menús de épocas lejanas.

NERUDA: "Con piedra y palo, cuchillo y cimitarra, con fuego y tambor avanzan los pueblos a la mesa. Los grandes continentes desnutridos con mil banderas, con mil independencias. $Y$ todo va a la mesa: el guerrero y la guerrera. Sobre la mesa del mundo, con todo el mundo a la mesa, volarán las palomas... Busquemos la mesa donde aprenda a comer el mundo. Donde aprendan a comer, a beber, a cantar. La mesa feliz. Hungría nos gustó y la gustamos. Somos golosos venidos de allá lejos, de tierras calientes que siguen ardiendo y tierras frías que viven con la nieve. Teníamos hambre ancestral, siglos de hambre maya, eda. des de hambre y guerra de Arauco, hambrunas de Castilla. Esas hambres caminan en nuestra sangre y nos dotaron de una curiosidad infinita por cuanto se come... En Budapest con su color de racimo y su alma de pan. .."

ASTURIAS: "La vida está sitiada en su castillo de frutas, de viandas, de pescados, de cames, de todo lo que constituye el contento de una buena mesa. El asalto final lo preparan científicamente los dietistas, estéticamente, los modistos, religiosamente, los ascetas y creyentes practicantes, económicamente, los mercaderes, cronométricamente, itinerarios 
y relojes. De las cocinas huyeron las horas amorosas de la preparación de los p!atos y pasteles, y la tristeza disfrazada de preocupaciones por la gordura, la línea, el pecado, el costo y el tener que estar a horario, acabó con lo que antes era grato y placentero, sentarse a comer..."

NERUDA: "Inolvidables berenjenas, lechugas saltadas, paprikas frescas en la ensalada vestida como una novia húngara, calabazas finas hasta olvidar su origen, convertidas en queso, en pastel, en sabor de oro, pepinos de agua pura, recién traídos de sus lechos de tierra o fermentados y agridulces, champiñones multiplicados por la lluvia en el bosque aromático, legumbres que al contacto del aceite, de las mantecas, del vinagre, de la sal y el fuego representan con maravillosa abundancia la tierra fecundísima.

ASTURIAS: "El Ancla". Foco decía su exterior del rincón que encontramos. Marineros de agua dulce, trabajadores del astillero, mujeres de ojos bellos y música. Mientras buscábamos una mesa, entre farolitos encendidos como las luces en los puentes de un barco, nos sedujo la idea, por la decoración, maderámenes, timón al centro, ambiente cerrado, compacto, de estar en el famoso ballenero que por aguas oceánicas persigue a las ballenas azules. En Hungría, y especialmente en Obuda, entrar en algunos restaurantes es abrir un libro de historia o leyendas heroicas en la ciudad tantas veces defendida, sitiada, tomada, quemada, destruida y reconstruida... En el "Ancla", para dejar intacta la construcción anti. gua, se recubrieron las paredes con maderámenes de viejos barcos, del suelo al techo, y estas maderas, al conjuro de los violines gitanos y de la fragancia del vino 'hoja de Tilo" de Debró, parecen susurrar historias lejanas de pescadores y marineros del Danubio. Aquí probamos por primera ver la "Carpa de Bandoleros".

NERUDA: "Así como la carpa, la humilde carpa, pez desapercibido entre los monseñores del agua, se eleva a categoría en la cocina hungárica, y entre tajadas, como papel imperial, al estragón, a la aidouk, a ra transilvania y hasta en crepés de gran dulzura. El repollo manda en la mesa campesina y se adereza en Budapest hasta la perfección del decoro, hasta el lujo. El repollo a la Kolozsvar es, como ditía Cerio, la obra maestra de Dios".

- Pero volvamos al poeta, dejemos lo anecdótico, y oigámosle: "A menudo expresé que el mejor poeta es el hombre que nos entrega el pan de cada día: el panadero más próximo que no se cree Dios. $\mathrm{El}$ cumple su majestuosa y humilde faena de amasar, meter al hotno, dorar y entregar el pan de cada día, como una obligación comunitaria. Y si el poeta llega a alcanzar esa sencilla conciencia, podrá también conver- 
tirse en parte de una colosal artesanía, de una construcción simple o complicada, que es la construcción de la sociedad, la transformación de las condiciones que rodean al hombre, la entrega de su mercancia: pan, verdad, vino, sueños. Si el poeta se incorpora a esa nunca gastada lucha por consignar cada uno en manos de los otros su ración de compromiso, su dedicación y su ternura al trabajo común de cada día y de todos los hombres, el poeta tomará parte, los poetas tomaremos parte en el sudor, en el pan, en el vino, en el sueño de la humanidad entera. Sólo por ese camino inalienable de ser hombres comunes llegaremos a restituirle a la poesía, el anchuroso espacio que le van recortando en cada época, que le vamos recortando en cada época nosotros mismos".

Nos vamos haciendo, que es lo que me propuse, una imagen de Pablo Neruda que difiere mucho de lo que se ha dicho y se dice de él. $\mathrm{Y}$ volviendo al principio, al poeta que quiere nombrar todas las cosas, para apropiárselas, por la palabra, arte mágico de nuestros antepasados, Neruda explicó en Estocolmo, al recibir el Premio Nobel: "Necesitamos colmar (yo decía poblar) de palabras los confines de un Continente mudo y nos embriaga esta tarea de fabular y de nombrar. Tal vez esa sea la razón determinante de mi humilde caso individual; y en esa circunstancia mis excesos, o mi abundancia, o mi retórica, no vendrían a ser sino actos de los más simples del menester americano de cada día. Cada uno de mis versos quiso instalarse como un objeto palpable: cada uno de mis poemas pretendió ser un instrumento útil de trabajo; cada uno de mis cantos aspiró a servir en el espacio, como un signo de reunión donde se cruzaron los caminos".

La necesidad de terminar. Queda tanto por decir, en este diálogo, amparados por la frase de Rimbaud, que recordara Pablo en su discurso de Estocolmo: "Sólo con ardiente paciencia conquistaremos la espléndida ciudad que dará luz, justicia y dignidad a todos los hombres".

$\mathrm{Y}$ la conquistaremos.

Miguel ANgel Asturias

Paris, 1972. 